\title{
Voyages badins, burlesques et parodiques du XVIII siècle, textes réunis et présentés par Jean-Michel Racault
}

\section{Marisa Ferrarini}

\section{(2) OpenEdition}

\section{Journals}

\section{Edizione digitale}

URL: https://journals.openedition.org/studifrancesi/45819

DOI: 10.4000/studifrancesi.45819

ISSN: 2421-5856

\section{Editore}

Rosenberg \& Sellier

\section{Edizione cartacea}

Data di pubblicazione: 1 octobre 2007

Paginazione: 440

ISSN: 0039-2944

\section{Notizia bibliografica digitale}

Marisa Ferrarini, «Voyages badins, burlesques et parodiques du xvIII siècle, textes réunis et présentés par Jean-Michel Racault», Studi Francesi [Online], 152 (LI | II) | 2007, online dal 30 novembre 2015, consultato il 24 novembre 2021. URL: http://journals.openedition.org/studifrancesi/45819 ; DOl: https://doi.org/10.4000/studifrancesi.45819

Questo documento è stato generato automaticamente il 24 novembre 2021.

\section{(c) (i) (9)}

Studi Francesi è distribuita con Licenza Creative Commons Attribuzione - Non commerciale - Non opere derivate 4.0 Internazionale. 


\title{
Voyages badins, burlesques et parodiques $\mathrm{du} X \mathrm{XVII} \mathrm{e}^{\mathrm{e}}$ siècle, textes réunis et présentés par Jean-Michel Racault
}

\author{
Marisa Ferrarini
}

\section{NOTIZIA}

Voyages badins, burlesques et parodiques $d u$ XVIII siècle, textes réunis et présentés par JeanMichel RACAULT avec la collaboration de Theodore E.D. BRAUn, Pierre BURGER et Erik LEBORGNÉ, Saint-Étienne, Publications de l'Université de Saint-Étienne, 2005, pp. 298.

1 Presentare una silloge di testi sui viaggi che intrattenevano gli «habitués» dei salotti nel Settecento è senz'altro una scommessa. Primo perché la distanza è grande, secondo perché i viaggi da sempre piacciono, terzo perché costituiscono un banale argomento di conversazione. A noi manca però la nota di lievità che il presente volume insuffla $\mathrm{e}$ soprattutto la curiosità della scoperta.

2 Jean-Michel Racault, noto specialista di Bernardin de Saint-Pierre e di letteratura di viaggi, con questa antologia di cui è curatore, con la collaborazione di Theodore E. D. Braun, Pierre Burger e Erik Leborgne, vince alla grande la scommessa. Non solo si propone di rendere nuovamente accessibili al lettore titoli un tempo noti e per alcuni anche celebri, con corredo di note per facilitarne la comprensione, ma di illustrare dagli albori al declino l'evoluzione di un genere: il «voyage littéraire en vers et en prose». È per questo che il libro si apre con il Voyage de Chapelle et Bachaumont (pp. 33-72), pubblicato nel 1663, ma generatore di una serie di echi e imitazioni sino alla fine del XVIII secolo, e si conclude con la Quête du blé di Venance Dougados, apparsa nel 1786-1788 (pp. 271-292). 
Cosa accomuna viaggi così diversi? Il primo narra con brio e naturalezza il lungo giro effettuato in Linguadoca e in Provenza, nel 1656 (o forse nel 1655) da Claude-Emmanuel Luillier alias Chapelle, autore di versi galanti e legato al libertinismo, e dall'amico suo François Le Coigneux de Bachaumont, magistrato mondano e, come lui, appassionato di letteratura e di piaceri, per raggiungere le terme di Encausse e trarne beneficio. Inutile dire che il testo non parla affatto di cure mediche e di efficacia delle terapie termali (alla faccia di Montaigne il cui tempo sembra ormai trascorso), ma indugia sulle bellezze femminili locali, sull'accoglienza ricevuta da parte degli ospiti più altolocati, tra cui Gaston d'Orléans, fratello di Luigi XIII, implicato nella Fronda indi esiliato, e il povero D'Assoucy accusato di impotenza dalle donne di Montpellier nonché sorpreso in compagnia di un dolce paggio. Giunti alla volta di Lione i due viaggiatori inviano il racconto delle loro peregrinazioni ai fratelli du Broussin, apprezzati gastronomi rimasti a Parigi, sotto forma di una lunga lettera in prosa e in versi, palesemente destinata a circolare tra pochi eletti. Rispetto ai due, l'autore della Quête du blé, ou voyage du P. Venance Dougados, capucin, dans différentes parties des diocèses de Vabres, Castres et SaintPons è pressoché uno sconosciuto appartenente al popolino. Ma anch'egli racconta con verve, in un'epistola indirizzata alla Viscontessa de Pins, figlia del suo protettore, le deambulazioni trascorse come frate questuante nel «Midi» della Francia alla fine delle messi, epoca in cui «Chaque individu séraphique, | Docile aux vœux que nous faisons, | S'en va, perché sur sa bourrique, | Quêter des grains et des affronts» (p. 272). La forma scelta è la stessa, così come il tono volutamente parodico, anche se J.-M. Racault, al di là dell'ovvio legame che istituisce con il Don Chisciotte, non riesce a porre bene in evidenza la vena del picaresco, come motivo di rivalsa sociale negli anni che immediatamente precedono la Rivoluzione.

4 Fatti a piedi, in carrozza, in chiatta fluviale o in nave, tutti i viaggi presenti nel volume (oltre ai due citati, nell'ordine: Relations du royaume de Candavia, 1715, pp. 73-112; Voyage de Languedoc et Provence di Le Franc de Pompignan, 1745, pp. 113-149; Voyage de Paris à Saint-Cloud di Louis-Balthazar Néel, 1748, pp. 151-207; Voyage de Bourgogne di Antoine de Bertin 1777, pp. 209-239; Voyage à Vile Bourbon di Évariste Parny, 1777, pp. 241-262) obbediscono a un unico schema. La scelta della forma epistolare per il resoconto di un viaggio fittizio o reale per divertire gli amici, il ricorso alla mitologia classica per estraniarsi dal reale, la tematica del buon vivere epicureo senza incorrere in sanzioni. Lasciamoci invogliare. 